[From the Prochedingis of the Royal Societr, No. 79, 1865.]

6) THE

\title{
EXISTENCE OF GLYCOGEN
}

TN THF

\section{TISSUES OF CERTAIN ENTOZOA。}

$\mathrm{B} \dot{\mathrm{Y}}$

MICHAEI, FOSTER, M.R.

Altuough glycogen has been found by various observers in the tissues of many of the Invertebrata, no one, as far as I know, has noticed the very remarkable amount which may be obtained from some of the Entozoa. I first came across this fact while working upon a tape-worm; unfortunately I neglected to determine the quantity of glycogen I obtained, and have not since had an opportunity of repeating the observation. The following remarks apply only to the round worm (Ascaris lumbricoides?) which dwells in the intestines of the common pig. 
By mincing and boiling in water, with a drop of dilute acetic acid, one of these animals, a decoction is obtained which remains milky-looking and opalescent after several filtrations, and therefore at once suggests the idea of glycogen. This milky fluid strikes a deep port-wine red with iodine, the colour disappearing on the application of heat, and reappearing on cooling, and gives no reduction when boiled with the alkaline coppersolution. When treated with saliva at $35^{\circ} \mathrm{C}$. the opalescence disappears, leaving a fluid either perfectly clear or exhibiting only a few flakes or a slight cloudy deposit (of some albuminoid material), but containing much sugar, as may be shown both by the copper and fermentation test.

If the original milky fluid be thrown into spirit, an abundant white flaky precipitate is thrown down, consisting partly of some albuminoid substance, but chiefly of a substance giving all the above reactions of glycogen. If the fluid be thrown into glacial acetic acid, a white flaky precipitate is thrown down consisting of nearly pure glycogen. The presence of glycogen may also be shown by employing the alcoholic solution of potash. From these facts we may infer that glycogen, and not dextrine merely, does exist in the bodies of these animals.

In no case have I found this gly cogen to be accompanied by anything more than a mere doubtful trace of sugar-that is to say, a trace of some substance giving a doubtful reduction of the copper-solution, and that by no means always. Hence, seeing how difficult it is to obtain glycogen in so pure a state that its quantity may be estimated directly by weighing, I have contented myself with determining the amount present in these animals by exposing a decoction to the influence of saliva until all traces of glycogen were lost, and then estimating by the copper process the amount of sugar produced. In this way I obtained from two ascarides weighing together, when taken fresh from the pig and merely wiped, 10.2 grms., and from three weighing together 10 grms., just $2 \cdot 2$ per cent. of sugar (on the wet weight) in each case. When this amount is compared with that produced by the mammalian liver alone, it will be seen that it really is, comparatively speaking, excessive. For the sake of comparing the Ascaris with other invertebrata, I may say that in a caterpillar weighing about 6 grms. I obtained a hardly appreciable quantity of glycogen, which was contained partly in the muscular parietes, and partly in the so-called "epiploon" or " hepatic parenchyma." The quantity of glycogen that I obtained from a handful of common maggots was also hardly appreciable.

In the Ascaris little or no glycogen is to be found in the intestine, a small quantity in the generative apparatus, and a very considerable quantity in the spongy visceral tissue; by far the largest amount exists in the firmer muscular parietes. I failed to detect with iodine any distinct histological localization.

It seems singular that an animal, living in the midst of a fluid one of whose chief functions is to change starch into sugar, should thus be found amassing glycogen within its own body. I have satisfied myself, however, 
that there is no sugar-forming ferment present in the tissues of the Ascaris. Portions of the tissues may be kept exposed to a temperature of $35^{\circ} \mathrm{C}$. for many hours without any appreciable loss of glycogen or advent of sugar. The whole animal, too, may be kept for days without any change of its glycogen being observed. I also failed to extract from the tissues any ferment capable of acting upon starch. The intestine alone seemed to have any power of the kind, and that but in the rery feeblest degree. This failure in the production of sugar is not due to the presence of any substance antagonistic to the action of a sugar-forming ferment; for the addition of a small quantity of saliva to even the unboiled tissues very speedily brings about the conversion of the glycogen into sugar. We may infer therefore that, if the animal swallows the intestinal juices in which it lives, the sugar-forming ferment contained therein either does not pass through its intestinal wall into the visceral cavity, or, if it does pass, is at once destroyed. It is evident that the formation of glycogen in the Ascaris takes place under conditions very different from those under which glycogen is deposited in the mammalian liver, since in the latter case there is present a powerful sugar-forming ferment belonging, as we have reason to believe, to the liver-substance itself, and not merely to the blood passing through the organ.

The possible use of this glycogen is a matter of interest. Intestinal worms, inasmuch as they are animals and live, must needs consume oxygen. The amount of that gas they find in the intestinal juices, however, is very small; and, having a constant temperature secured to them by warmth external to themselves, they are the very last of creatures to need what has been called " respiratory or calorifacient material." Whatever be the use of sugar, starch, or glycogen in the mammalian body, no "respiratory" use can be safely suggested for the large amount of glycogen occurring in the Ascaris. Its abundance in the muscular parietes might suggest that it was material on its way to become muscle. If so, since the animals I studied were adults and ova-producing, the analogy of their glycogen would be, not with the glycogen of the muscles of the early mammalian embryo, but with the glycogen (or dextrine) occurring in smaller quantities in the full-grown muscles (unless one were to push an idea, and say that the tissues of the lower animals were chemically homologous with the embryonic tissues of the higher ones).

It might be thought to be immature chitin; but why should it exist in such quantities? and why is there so little in the caterpillar and the maggot? In the Tænia the glycogen could hardly be thought to have a muscular future. There it might be considered to be stored up for the development of the ova. This idea is at first sight contradicted, as far as the Ascaris is concerned, by the fact that very little glycogen can be obtained from the generative apparatus of that animal. But is it not possible that, though stored up elsewhere, it may really be intended for the ova and embryos after all? The analogy between the Ascaris, with its 
glycogen, and a plant with its blanched starch-storing tissues, is striking in many ways. May not "migration," which plays so important a part in vegetable physiology, occur in the animal economy in reference to other substances besides fat? 
Digitized by the Internet Archive in 2019 with funding from Wellcome Library

https://archive.org/details/b30566861 
